\title{
Effects of Combined Exercise on Exercise Adherences and Health Self-Efficacy in Middle-aged Women
}

\author{
Ryewon $\mathrm{Ma}^{1}$ and Young-Ju Jee ${ }^{2}$ \\ Kyungnamdaehak-ro, Masanhappo-gu, Changwon-si, Gyeongsangnam-do, Republic \\ of Korea \\ ${ }^{1}$ mrw4023@kyungnam.ac.kr, ${ }^{2}$ jeeyoungju@kyungnam.ac.kr
}

\begin{abstract}
The purpose of this study was, therefore, to develop a combined exercise program to induce the participation of middle-aged women and to examine the effect of participation in the proposed program on health self-efficacy and exercise adherence. This study also intended to provide basic data on the development of effective exercise programs for the continuous health care of middle-aged women. The one-group pre-post experimental design was applied and the subjects were 20 middle-aged women aged 35 to 65 who participated in a combined exercise program administered by the S District Public Health Center in Busan Metropolitan City. The proposed program was 12 weekly exercise program composed of aerobic exercise, low-middle intensity muscle-strength exercise, and flexibility and balance exercise. The effectiveness of the program was measured by using a structured questionnaire on health self-efficacy and exercise adherence. The collected data were analyzed by using SPSS 23.0 program and the descriptive statistics and Wilcoxon sign rank were conducted. Participation in combined exercise programs had positive effects on health self-efficacy and exercise adherence, which is expected to induce continuous participation in exercise and active engagement with health management.
\end{abstract}

Keywords: Middle-aged women, Combined exercise, Health self-efficacy, Exercise adherence

\section{Introduction}

Middle-aged women who are located between maturity and old age during the development stages of life [1] experience changes in the role of the family, the social support system, and individuality in society, as well as physical ones such as aging and the onset of physical illness and to adapt to various changes in socio-psychological factors such as loss of relationship [1][2]. Menopause, which is experienced by middle-aged women, may cause various physical and mental changes, thus unless directly managed, making them vulnerable to many types of diseases [1]. In addition, considering that the health of this period affects the quality of life of the elderly, the importance of health care is also emphasized.

Regular exercise is an appropriate stimulus for the body, promoting physical health, such as the maintenance of daily activities, and reducing depression or stress in the aspects of

Article history:

Received (March 25, 2019), Review Result (April 26, 2019), Accepted (May 27, 2019) 
psychological health [3]. Exercise also has a social effect such as a decrease in health expenditure and an increase in social participation, as well as an improvement in well-being, inducing higher motivation for life [4].

Since exercise in middle-aged women has a close relationship with lifestyle [2] and plays an important role in improving the quality of life [5], it is important, in exercise selection, to choose an exercise that reflects various conditions such as the type and environmental condition of exercise and subject's willingness to participate in the exercise. The combined exercise is carried out in various ways, using tools that help increase exercise capacity, such as aerobic and resistance ones [6]. This type of exercise has the effect of reducing metabolic syndrome factors, strengthening cardiorespiratory fitness, and reducing cardiovascular risk factors, which are making this type of exercise to be a theme of extensive studies [7][8][9].

Even though the importance of exercise effects is accepted widely, continuous participation in exercise is so difficult that it is likely to stop exercise even before checking the effect of exercise. This means that continuous and active participation in the chosen exercise according to one's own needs is very important. Health self-efficacy is a perceived one's ability to perform tasks related to physical performance for health promotion [10] and is an important variable in sustaining exercise behavior. Although the importance of exercise as a means of health management in middle-aged women has been emphasized, research on the development and effects of exercise programs that increase their willingness to participate actively and continuously in these exercise programs has been very limited.

The purpose of this study was, therefore, to develop a combined exercise program to induce the participation of middle-aged women and to examine the effect of participation in the proposed program on health self-efficacy and exercise adherence. This study also intended to provide basic data on the development of effective exercise programs for the continuous health care of middle-aged women.

\section{Method}

\subsection{Subjects}

The subjects of this study were 20 middle-aged women aged 35 to 65 who participated in a combined exercise program administered by the S District Public Health Center in Busan Metropolitan City. The contents and procedures of the exercises were explained in detail and consent was acquired before enrollment in the study. The data were collected for about three months from 4th Sep. to 29th Nov. 2017.

\subsection{Procedure}

This group pre-post experimental study intended to investigate the effects of a 12-week combined exercise program on health self-efficacy and exercise adherence in middle-aged women. The general characteristics, health self-efficacy, and exercise adherence were premeasured one week before the exercise program and post-measurement was performed over the last week of the exercise program. To minimize the effects of extraneous variables on the results of this study, nutritional counseling was added during the program to instruct them to keep their eating habits unchanged during the program period and encouraged them not to participate in the additional exercise.

\subsection{Measurement}




\subsubsection{Health self-efficacy}

The Self-Rated Abilities for Health Practices Scale [10] translated, modified, and refined by Choi (2004) was used. This instrument is composed of 28 items and the higher scores indicate a higher level of health self-efficacy.

\subsubsection{Exercise adherences}

The Willingness to Adhere Exercise - Korean version developed by Choi (2005) was used. The tool consists of 17 items and measures five subscales of exercise ability, exercise habits, exercise environment, exercise interest, and exercise friend. The higher score indicates a higher level of direct participation or adherence without stopping.

\subsection{Combined exercise intervention}

A total of four specialists including a doctor specializing in physical education, an exercise prescription specialist, one social work practitioner, and a doctor specializing in adult nursing participated in the development of the proposed program. Stretching as warm-up and cooldown exercises before and after the main exercise were added. The main exercises include aerobic exercise (body exercise, stretching, step box), low-middle intensity exercise (core exercise, thera-band, kettle-bell), and flexibility and balance exercise (yoga). The program consisted of three sessions per week for 12 weeks and it takes about 60 minutes in completing a session.

\subsection{Statistic}

The collected data were analyzed using SPSS 23.0 program. The pre and post-program mean and standard deviations of the subjects' health self-efficacy and exercise adherence were used in the level of the corresponding variables. The Wilcoxon signed rank test was conducted to test the ranks of pre- and post-experimental effect

\section{Results}

\subsection{General characteristics}

The mean age of the subjects was $58.35( \pm 7.17)$ years old. For the educational level, $45 \%$ $(n=9)$ reported high school graduation and $25 \%(n=5)$ reported university graduates. For marital status, almost $(\mathrm{n}=18 ; 90 \%)$ were married.

\subsection{Difference in health self-efficacy and exercise adherence between pre-and post- combined exercise program intervention.}

The result of the difference test in subjects' health self-efficacy showed a significant difference in nutritional efficacy between pre- and post-program, indicating an increase in nutritional efficacy after the program.

For exercise adherence, the exercise habit $(Z=-2.63, \mathrm{p}<.01)$ and exercise interest $(Z=-3.06$, $\mathrm{p}<.01)$ showed a significant difference between pre-and post-program and the willingness to exercise adherence measured by total score showed a significant increase after the program $(\mathrm{Z}=-2.75, \mathrm{p}<.01)$. 
Table 1. Effectiveness of exercise on exercise adherence and health self-efficacy

\begin{tabular}{|c|c|c|c|c|c|}
\hline \multirow{4}{*}{ Variable } & Sub-Categories & Pre & Post & \multirow{2}{*}{$\mathrm{z}$} \\
\cline { 2 - 6 } & Exercise & $\mathrm{M}(\mathrm{SD})$ & $\mathrm{M}(\mathrm{SD})$ & & .95 \\
\hline \multirow{3}{*}{$\begin{array}{c}\text { Health } \\
\text { Self- } \\
\text { Efficacy }\end{array}$} & Psychological Well Being & $2.94(.29)$ & $3.02(.28)$ & -1.42 & .16 \\
\cline { 2 - 6 } & Nutrition & $2.78(.29)$ & $2.93(.31)$ & $-2.25^{*}$ & .03 \\
\cline { 2 - 6 } & Responsible Health Practices & $2.87(.35)$ & $2.95(.40)$ & -.95 & .34 \\
\cline { 2 - 6 } & Total Score & $2.88(.19)$ & $2.96(324)$ & -1.34 & .18 \\
\hline \multirow{3}{*}{$\begin{array}{c}\text { Exercise } \\
\text { Adherence }\end{array}$} & Exercise Abilities & $3.20(.67)$ & $3.24(.74)$ & -.41 & 0.69 \\
\cline { 2 - 6 } & Exercise Habits & $3.13(.68)$ & $3.43(.58)$ & $-.2 .63^{* *}$ & $<.01$ \\
\cline { 2 - 6 } & Exercise Environments & $3.49(.53)$ & $3.64(.50)$ & -.71 & .48 \\
\cline { 2 - 6 } & Exercise Concern & $2.92(.58)$ & $3.35(.67)$ & $-3.06^{* *}$ & $<.01$ \\
\cline { 2 - 6 } & Exercise Partners & $3.38(.46)$ & $3.53(.58)$ & -1.48 & .14 \\
\hline
\end{tabular}

\section{Conclusion}

In this study, the effects of 12 weeks of combined exercise on health self-efficacy and willingness to exercise adherence in middle-aged women. The results showed a significant increase in nutritional efficacy, a subscale of health self-efficacy, after the program. For exercise adherence, the total score as well as subscales of exercise habit and exercise interest increased significantly after the program.

Exercise plays a very important role in improving the quality of life in all age groups. This exercise is more important in middle-aged women because they are subjected to various physical and psychological diseases due to menopause in the course of transition to the elderly. Although the effects of exercise may be improved through manipulating the intensity, the number of times is more emphasized than the intensity. The willingness to participate in and interest in exercise are also important factors.

The combined exercise applied in this study increased the willingness to exercise adherence in middle-aged women, however, failed in improving the health self-efficacy on exercise. It is urgent to provide a program that induces adults to participate actively and selfdirectly in exercise and lead a healthy life by themselves. Future research are recommended to investigate the effect of exercise widely by adding physical variables.

\section{Acknowledgments}

This study was funded by research grants for new professors at Gyeongnam University.

\section{References}

[1] M.J. Kim, Midlife development, Kyomoonsa, (1989).

[2] D.J. Kim, "The relationship among perceived health status, life satisfaction, and health promotion behavior in physical activity participants in middle age," Journal of Sport and Leisure Studies, Vol.47, No.1, pp.503-518, (2012) 
[3] S. Vaughan, M. Wallis, D. Polit, M. Steele, and D. Shum, "The effects of multimodal exercise on cognitive and physical functioning and brain-derived neurotrophic factor in older women: A randomized controlled trial,” European Journal of Pharmacology, vol.24, no.7, pp.1144-1151, (2014)

[4] Y.H. Moon, "The effect of an exercise program on the physical, physiological and emotional status of the aged," Journal of Korean Academy of Community Health Nursing, vol.17, no.4, pp.451-460, (2006)

[5] I.W. Kang and W.J. Cho, "The influence on mental health status and health-related quality of life in middleaged women by the regular walking exercise: By based on the Korea National Health and Nutrition Examination Survey(KNHANES VI),” Korea Society for Wellness, vol.11, no.1, pp.207-215, (2016)

[6] S.M. Grundy, J.I. Cleeman, C.N. Merz, H.B. Brewer, L.T. Clark, D.B. Hun, et al., "Implications of recent clinical trials for the national cholesterol education program adult treatment panel III guidelines," J Am Coll Cardiol, vol.44, no.3, pp.720-732, (2004)

[7] J. Pintar, R. Robertson, A. Kriska, E. Nagle, and F.L. Goss, "The influence of fitness and body weight on preferred exercise intensity,” Med Sci Sports Exerc, vol.38, no.5, pp.981-988, (2006)

[8] S.K, Park, Y.Kwon, E.Kim, and S. Lee, "The effect of combined training on abdominal fat, physical fitness, and resistin concentration in aged visceral obese women," Korea Sport Res, vol.17, no.3, pp.237-250, (2006)

[9] B.K. Yu, "The change of severely obese middle-aged women's body fat, cardiovascular strength, and blood hormone on the combined exercise," J Exerc Nutrition Biochem, vol.9, no.3, pp.253-259, (2005)

[10] H. Becker, A. Stuifbergen, H. Oh, and S. Hall, "Self-rated abilities for health practices: A health self-efficacy measure," Health Values: The Journal of Health Behavior, Education \& Promotion, vol.17, no.5, pp.42-50, (1993) 
This page is empty by intention. 